\title{
Retrospective Investigation of Anticoagulant Complications in Long Term after Mechanical Heart Valve Replacement Surgery in Turkey
}

\author{
Eda Ayten Kankaya ${ }^{1,2, *}$ (iD) , Özlem Bilik ${ }^{3}$ and Tuğra Gençpınar4 ${ }^{\text {(iD }}$ \\ ${ }^{1}$ Department of Surgical Nursing, Dokuz Eylül University Nursing Faculty, İzmir, Turkey \\ 2 PhD Candidate, Research Assistant, Department of Surgical Nursing, Graduate School of Health Sciences, Dokuz Eylül University, İzmir, Turkey \\ 3 Associate Professor, Department of Surgical Nursing, Nursing Faculty, Dokuz Eylül University, İzmir, Turkey \\ ${ }^{4}$ Associate Professor, Department of Thoracic and Cardiovascular Surgery, Faculty of Medicine Surgery, Dokuz Eylül University, İzmir, Turkey
}

* Corresponding author: Eda Ayten Kankaya, Department of Surgical Nursing, Dokuz Eylül University Nursing Faculty, İzmir, Turkey. Email: edayten@gmail.com

Received 2020 November 09; Revised 2020 December 02; Accepted 2020 December 18.

\begin{abstract}
Background: Patients with mechanical heart valve replacement surgery (MHVRS) should be followed up in terms of prosthetic valverelated and open heart surgery complications.

Objectives: This study aimed to determine the anticoagulant complications in long term in patients with MHVRS.

Methods: This retrospective and descriptive study was conducted in a university hospital, Izmir, Turkey. The data were collected from July to December 2019. In total, 73 patients referring for regular check-ups to the hospital with intervals not exceeded more than 90 days, and those who had international normalized ratio (INR) measurements for January-April-July-October 2018 were included in this study. Results: The mean age of the patients was obtained at $58.98 \pm 12.89$ years, and $53.4 \%(n=39)$ of the cases were male. Moreover, the mean follow-up period was estimated at $65.98 \pm 28.47$ months. According to the results, complications developed in 60 patients $(82.2 \%)$. The first hospitalized unit was the emergency department. The factors affecting the development of complications after MHVRS were evaluated, and a difference was found regarding gender $\left(X^{2}=6.18, P=0.013\right)$, comorbidities $\left(X^{2}=25.58, P=0.018\right)$, and monthly referral for regular check-ups to the hospital $\left(\mathrm{X}^{2}=5.20, \mathrm{P}=0.023\right)$. There was no relationship between the INR levels and the development of complications. Furthermore, the results of evaluating the factors affecting the number of hospitalizations after MHVRS revealed that monthly referral to hospital for check-ups $(\mathrm{t}=3.18, \mathrm{P}=0.002)$ and history of previous valve surgery $(\mathrm{Z}=201.00, \mathrm{P}=0.03)$ affected the number of hospitalizations.

Conclusion: It was observed that patients frequently refer to the emergency department and struggled with various complications. Moreover, it was found that the patients had frequent bleeding and refer to the emergency service repeatedly. Accordingly, there is a need for interventional studies to reduce postoperative complications and provide the therapeutic INR level.
\end{abstract}

Keywords: Cardiac surgical procedures, Complication, Disease, Heart valve, Prosthesis

\section{Background}

Heart valve diseases are among the common health problems, and surgical treatment is the foreground for advanced valve diseases (1). Patients with mechanical heart valve surgery should be followed up in terms of the prosthetic valve and open heart surgery-related complications. In the long term, complications, such as heart failure, infective endocarditis, sternal wound infections, neurological complications, valve-related complications, acute renal failure, and sepsis can be observed due to open-heart surgery $(2,3)$. Following these complications, problems, such as valve thrombosis, thromboembolism, and bleeding, may occur with mechanical prosthesis.

Warfarin, a vitamin $\mathrm{K}$ antagonist, is also used in Turkey for anticoagulation. The efficacy and safety of warfarin depend on the ratio of the international normalized ratio (INR). The INR follow-up of these patients is very important, followed by bleeding and thrombosis occurrence when the INR is out of the safe range (4-6). In a cohort study, the incidence rates of thromboembolism and bleeding were estimated at
1.8 and 2.2, as well as 4.4 and 4.6 in patients with aortic valve replacement (AVR) and mitral valve replacement (MVR), respectively (7). In a prospective study, INR values less than 2.0 significantly increased the rate of thromboembolism. Moreover, the INR values between 3.0 and 4.0 or $>4.0$ were found to increase moderate and major bleeding, respectively $(8)$. The cross-sectional $(9,10)$ and prospective studies $(11,12)$ in Turkey have been reached which patients' knowledge levels related warfarin use. In a study, regular follow-up and training improved warfarin efficacy, patient satisfaction, and quality of life (13). Çelik et al. found that Turkish society had low awareness of warfarin, and there was a difference in time in the therapeutic range (TTR) according to the regions. Moreover, bleeding was most common in the Aegean region, it was reported that they could not record embolic complications (12).

After evaluating the studies in Turkey, no retrospective studies were found to investigate the complications of patients with mechanical heart valve replacements (MHVRS) in the long term. The reasons 
for which MHVRS patients were hospitalized for at least one year after surgery and repeated hospitalizations as well as the INR levels by months were among the novelties of this study.

\section{Objectives}

This study aimed to determine the complications in patients with MHVRS in the long term that use lifelong anticoagulants. Since all complications were examined in the present study, the findings would be beneficial in the long-term follow-up and MHVRS patients' care. Moreover, it is believed that the results will contribute to the literature on the side effects of warfarin.

\section{Methods}

This cross-sectional study was conducted based on a retrospective and descriptive method in a university hospital. The data were collected between January and December 2019 using the "Hospital İnformation System" and the medical history of each patient. Since medical records were not collected in a single-center across the country, this study collected data that have been available since 2010 using only the "Hospital Information System" in the university hospital.

Since the hospital in which the study was conducted was a university hospital, the majority of the patients reside outside of the province and were followed up in hospitals close to them after the surgery. Therefore, 73 patients with MHVRS were included in the study from 2010 to 2017. The inclusion criteria were: 1) 18 years of age or older, 2) referral for regular check-ups in the hospital, 3) previous MHVRS, 4) no more than a 90-day interval between polyclinic check-ups, 5) a history of at least 1 year after surgery, and 6) INR test results for January-April-July-October 2018 in the hospital information system

On the other hand, the patients with no medical records of postoperative controls were excluded from the study. Due to the retrospective nature of this study, only medical records were examined to avoid errors in patients' recall of historical information.

\subsection{Data Collection Form}

The researcher-made form was prepared according to the literature $(1,12)$ to cover such information as age, gender, MRV type, place of residence, time after surgery (months), existing high-risk diseases, the average frequency of coming to outpatient clinic controls, INR values in January-April-July-October 2018, the first hospitalization after discharge and MHVRS, the number of hospitalizations, and the reasons for hospitalization. The researcher recorded the data obtained from the "Hospital Information System" in the collection form.

\subsection{Statistical analysis}

The data were analyzed in SPSS software (version 25.0), and the sociodemographic characteristics were represented as numbers, percentages, and arithmetic mean.

Furthermore, Pearson correlation analysis was utilized to evaluate the relationship among age, postoperative time, the first rehospitalization time, and the total number of hospitalizations. Additionally, the difference between the number of hospitalizations and the valve type was determined by the Kruskal Wallis test, and the Man Whitney U test was used to examine the association of the number of hospitalizations with the presence of comorbidity and previous valve surgery. Moreover, the correlation between monthly visits and the number of hospitalizations was evaluated using a t-test in the independent groups.

The presence of complications was examined using the Chi-square test according to gender, comorbidities, monthly hospital visits, valve type, history of previous valve surgery, and INR values in certain months in 2018.

\subsection{Ethical Considerations}

The required permissions were taken from the hospitals where the study was conducted (Dokuz Eylul University Hospital, Izmir, Turkey). Moreover, the study protocol was obtained from the Ethics committee for Noninvasive Clinical Studies of Dokuz Eylul University, Izmir, Turkey (3659;2017/2709;27.11.2017).

\section{Results}

The mean age of the patients was obtained at $58.98 \pm 12.89$ years, and $53.4 \% \quad(n=39)$ of the patients were male. All patients were living in Izmir, Turkey, and the mean follow-up period was estimated at $65.98 \pm 28.47$ months. Moreover, the time of the first rehospitalization was determined at $7.06 \pm 10.41$ months. The majority of the patients $(\mathrm{n}=49 ; 67.12 \%)$ had undergone a single MHVRS, and the most common operation was MVR $(n=26$; $35.6 \%)$. In multiple mechanical prosthesis surgeries, the majority $(n=17 ; 23.3 \%)$ of the patients underwent AVR+MVR surgery. Furthermore, $84 \%$ of the patients $(n=62)$ had chronic diseases, and the most common diseases were hypertension $(n=34$, $46.6 \%$,), congestive heart failure $(n=25,34.13 \%)$, and dysrhythmia $(n=20 ; 27.35 \%$,). It is worth mentioning that $41(56.2 \%)$ patients did not refer for the monthly hospital check-ups, and 11 (15.1\%) individuals had previous valve surgery. Postoperative complications developed in 60 patients (82.2\%), and 41 (56.2\%) patients were first admitted to the emergency department (ED).

After evaluating the reasons for hospitalizations at the ED, it was found that the most common reasons 


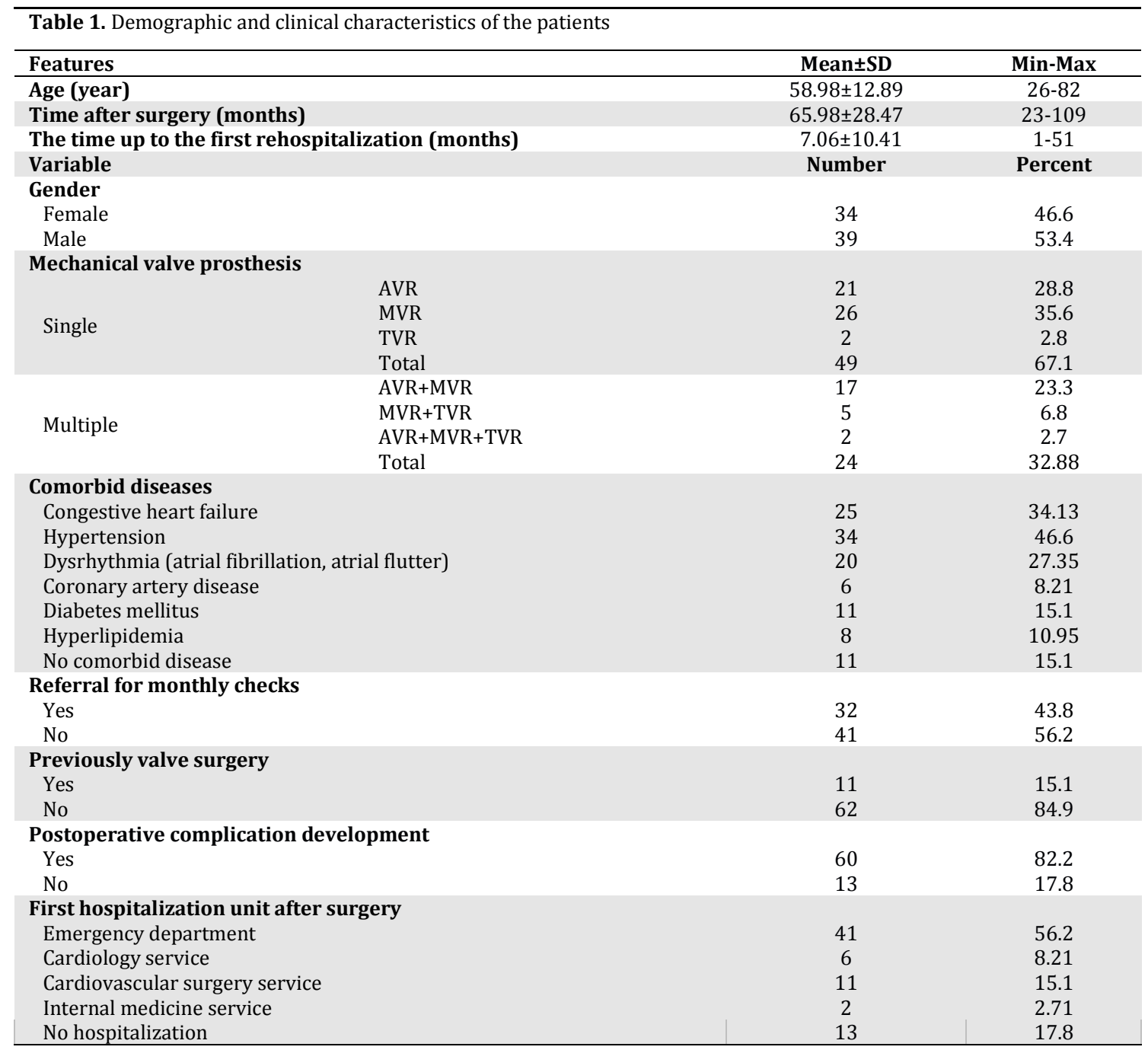

were cardiovascular complaints and bleeding. Furthermore, regarding the repeated hospitalization, 36 (49.31\%), 25 (34.13\%), 18 (24.65\%), and 13 (18.06\%) patients were admitted to the hospital for the second, third, fourth, and fifth times, respectively (Table 2).

The reasons for hospitalization at the cardiology service included heart failure, valve thrombosis, and pericardial hematoma. Additionally, wound infection, signs of heart failure, valve thrombosis, overdose, and infective endocarditis/pericarditis were the reasons for admission to the cardiovascular surgery service. Cerebrovascular disease, as well as intracranial and subdural hematoma, were the most common reasons for hospitalization in the neurology clinic (Table 3 ). In addition, a female patient was admitted to the

Table 2. Symptoms that cause patients to be admitted to the emergency department and examination of symptoms according to the order of admission

\begin{tabular}{|c|c|c|c|c|c|c|c|}
\hline \multirow{2}{*}{$\begin{array}{l}\text { Reasons for admission } \\
\text { to the emergency } \\
\text { department } \\
\text { Cardiovascular causes }\end{array}$} & Symptoms & \multicolumn{2}{|c|}{$\begin{array}{c}\text { 1 st } \\
\text { admission } \\
n \quad(\%)\end{array}$} & $\begin{array}{c}\text { 2nd } \\
\text { admission } \\
n \quad(\%)\end{array}$ & $\begin{array}{c}\text { 3th } \\
\text { admission } \\
\text { n } \quad(\%)\end{array}$ & $\begin{array}{c}\text { 4th } \\
\text { admission }\end{array}$ & $\begin{array}{c}\text { 5th } \\
\text { admission } \\
\text { n } \quad(\%)\end{array}$ \\
\hline & Palpitations, dyspnea, chest pain & 23 & $(31.50)$ & $15(20.54)$ & $12(16.43)$ & $7(9.58)$ & $4(5.47)$ \\
\hline \multirow{9}{*}{ Bleeding } & Hematuria & 1 & $(1.34)$ & $4 \quad(5.47)$ & - & - & $1(1.34)$ \\
\hline & Epistaxis & 5 & $(6.84)$ & 8 (10.95) & $(8.21)$ & $(4.10)$ & $2(2.71)$ \\
\hline & Mouth/gingival bleeding & 3 & $(4.10)$ & $(2.71)$ & - & $(2.71)$ & $2(2.71)$ \\
\hline & Melena/ rectal bleeding & 3 & $(4.10)$ & - & $(2.71)$ & - & $2(2.71)$ \\
\hline & Hematochezia & 2 & $(2.71)$ & - & - & - & - \\
\hline & Petechiae & 1 & $(1.34)$ & $(1.34)$ & - & $(1.34)$ & - \\
\hline & Ear bleeding & & - & $(2.71)$ & - & $(1.34)$ & - \\
\hline & Conjectival bleeding & & - & $(1.34)$ & $(1.34)$ & - & - \\
\hline & Bleeding symptoms total & 15 & $(20.43)$ & $18(24.52)$ & $9(12.26)$ & $(9.49)$ & $7(9.47)$ \\
\hline \multicolumn{2}{|c|}{ Cerebrovascular disease symptoms } & 6 & $(8.21)$ & $(2.71)$ & $(4.10)$ & $(2.71)$ & $1(1.34)$ \\
\hline \multicolumn{2}{|l|}{ Overdose } & 2 & $(2.71)$ & $(1.34)$ & $(1.34)$ & $(2.71)$ & $1(1.34)$ \\
\hline \multicolumn{2}{|l|}{ Total } & 46 & $(63.1)$ & $36(49.31)$ & $25(34.13)$ & $18(24.65)$ & $13(18.0)$ \\
\hline
\end{tabular}




\begin{tabular}{|c|c|c|c|}
\hline Reasons for hospitalization & $\begin{array}{c}\text { Cardiology } \\
\text { n (\%) }\end{array}$ & $\begin{array}{c}\text { Cardiovascular surgery } \\
\text { n (\%) }\end{array}$ & $\begin{array}{c}\text { Neurology } \\
\text { n (\%) }\end{array}$ \\
\hline Heart failure symptoms & $13(18.06)$ & $3(4.10)$ & \\
\hline Valve thrombosis & $2(2.71)$ & $3(4.10)$ & \\
\hline Pericardial hematoma & $1(1.34)$ & - & \\
\hline Wound infection & & $8(10.95)$ & \\
\hline Overdose & & $3(4.10)$ & \\
\hline Infective endocarditis/pericarditis & & $3(4.10)$ & \\
\hline Subdural hematoma & & & $1(1.34)$ \\
\hline Cerebrovascular disease & & & $9(12.32)$ \\
\hline Intracranial hematoma & & & $2(2.71)$ \\
\hline Total & $16(22.91)$ & $20(27.35)$ & $12(16.43)$ \\
\hline
\end{tabular}

gynecology and obstetrics due to abortion after vaginal bleeding, and another patient was admitted to the infection service due to postoperative sepsis.

When the factors affecting the development of complications after MHVRS were examined, a difference was found regarding gender, and more complications were found in female patients $\left(X^{2}=6.18, \quad P=0.013\right)$. Moreover, the number of hospitalizations of patients with comorbidities was found to be higher, which was statistically significant $\left(\mathrm{X}^{2}=25.58, \mathrm{P}=0.018\right)$. There was a difference between monthly visits and the development of complications $\left(\mathrm{X}^{2}=5.20, \mathrm{P}=0.023\right)$. However, no difference was observed between the development of complications depending on whether the INR values were in the therapeutic range by months.

When therapeutic INR values by months were examined, it was determined that the number of people with higher therapeutic INR values was higher in July, compared to the other months, while the number of people with lower therapeutic INR values was higher in January (Table 4).

The factors affecting the number of hospitalizations post MHVRS were evaluated in this study. The results revealed the high number of hospitalizations of the patients who referred for monthly check-ups (3.84 \pm 2.50$)$, which was statistically significant $(t=3.18$, $\mathrm{P}=0.002$ ). Furthermore, the patients with a previous history of valve surgery had more hospitalizations $(\mathrm{Z}=201.00, \mathrm{P}=0.03)$. No correlation was found among age, the time of the first rehospitalization, and the number of hospitalizations. However, a low-level positive and significant relationship was found between the postoperative time and the number

\begin{tabular}{|c|c|c|c|c|}
\hline \multirow{2}{*}{ Variables } & & \multicolumn{2}{|c|}{ Complication development } & \multirow{2}{*}{$\mathbf{X}^{2} / \mathbf{p}$} \\
\hline & & Yes (n) & No (n) & \\
\hline \multicolumn{5}{|l|}{ Gender } \\
\hline Female & & 32 & 2 & \multirow{2}{*}{$6.18 / 0.013^{*}$} \\
\hline Male & & 28 & 11 & \\
\hline \multicolumn{5}{|c|}{ Comorbid diseases } \\
\hline With com & & 53 & 7 & \multirow{2}{*}{$5.58 / 0.018^{*}$} \\
\hline Without & lity & 8 & 5 & \\
\hline \multicolumn{5}{|c|}{ Referal for monthly checks } \\
\hline Yes & & 30 & 2 & \multirow{2}{*}{$5.20 / 0.023^{*}$} \\
\hline No & & 30 & 11 & \\
\hline \multicolumn{5}{|c|}{ Type of mechanical valve prosthesis } \\
\hline Single & & 39 & 10 & \multirow[b]{2}{*}{$0.68 / 0.52$} \\
\hline Multiple & & 21 & 3 & \\
\hline \multicolumn{5}{|c|}{ Previous valve surgery } \\
\hline Yes & & 11 & 0 & \multirow{2}{*}{$2.80 / 0.19$} \\
\hline No & & 49 & 13 & \\
\hline \multicolumn{5}{|l|}{ Months } \\
\hline \multirow{3}{*}{ January } & Under therapeutic range & 12 & 3 & \multirow{3}{*}{$0.76 / 0.68$} \\
\hline & Time in therapeutic range & 43 & 8 & \\
\hline & Over therapeutic range & 5 & 6 & \\
\hline \multirow{3}{*}{ April } & Under therapeutic range & 10 & 2 & \multirow{3}{*}{$0.31 / 0.85$} \\
\hline & Time in therapeutic range & 36 & 7 & \\
\hline & Over therapeutic range & 14 & 4 & \\
\hline \multirow{3}{*}{ July } & Under therapeutic range & 7 & 3 & \multirow{3}{*}{$1.86 / 0.39$} \\
\hline & Time in therapeutic range & 35 & 8 & \\
\hline & Over therapeutic range & 18 & 2 & \\
\hline \multirow{3}{*}{ October } & Under therapeutic range & 9 & 2 & \multirow{3}{*}{$0.02 / 0.98$} \\
\hline & Time in therapeutic range & 36 & 8 & \\
\hline & Over therapeutic range & 15 & 3 & \\
\hline
\end{tabular}

$\mathbf{X}^{2}=$ Pearson's Chi-square test, ${ }^{*} \mathrm{P}<0.05$. 


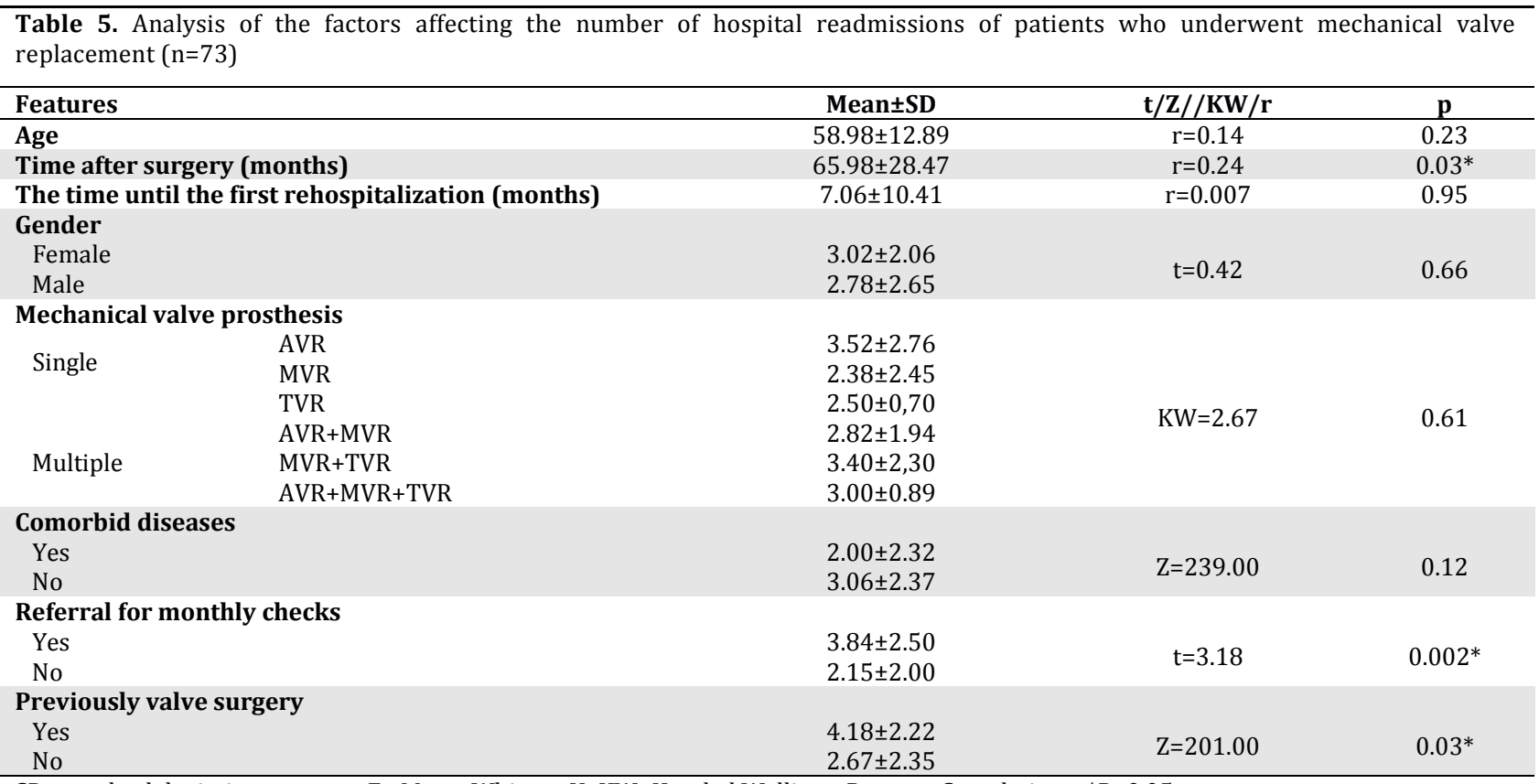

SD, standard deviation; $\mathrm{t}=\mathrm{t}$ test; $\mathrm{Z}=$ Mann-Whitney U; KW=Kruskal Wallis; $\mathrm{r}=$ Pearson Correlation; ${ }^{*} \mathrm{P}<0.05$

of hospitalizations (Table 5). The number of hospitalizations increases, followed by an increase in the duration of the problems after surgery.

\section{Discussion}

This study was carried out to determine complications in long term among MHVRS patients who used lifetime anticoagulants. The medical records of 73 patients who passed at least 1 year after surgery and did not exceed 90 days in the outpatient clinic check-ups were retrospectively analyzed in this study.

It was important for patients to refer monthly for check-ups after surgery so that the INR could be followed up. In our study, $43.8 \%(n=32)$ of the patients referred monthly for check-ups. In a study conducted in India, this rate was estimated at $37.1 \%$ $(\mathrm{n}=89)$. Similarly, in a study conducted in Turkey, $26.22 \%(n=32)$ of the patients who received warfarin treatment did not refer for regular check-ups (14). It was believed that the lack of referral for monthly check-ups was due to a lack of information about the effects and side effects of warfarin (9).

In our study, postoperative complications developed in $82.2 \%(n=60)$ of the patients, and they were first admitted to the ED due to complications (Table 1). Regarding the reasons for admission to the $\mathrm{ED}$, failure and bleeding were the most significant reasons, while the symptoms of cerebrovascular disease and overdose were other causes in this regard (Table 2). In our study, epistaxis was the most common type of bleeding in patients. In another study, the patients using warfarin $(n=518)$ mostly had gastrointestinal system bleeding $(21.8 \%, \mathrm{n}=113)(15)$. In the same line, in a cohort study involving 450 mechanical AVR patients, gastrointestinal, cerebral, and urologic bleeding were observed in 15,7 , and 3 patients, respectively (4). A study was conducted on 114 patients who used warfarin and were admitted to the ED due to bleeding. The results revealed that $42.1 \%$ of the patients referred regularly for check-ups.

Moreover, it was emphasized that $37.7 \%$ of the patients knew that they had to undergo a laboratory test (16). The reasons why the patients are readmitted to the ED can be attributed to their lack of knowledge and awareness. On the other hand, when the researchers analyzed the reasons, it was determined that the complications related to warfarin were generally examined in the ED; however, other causes were not assessed in this department.

Researches analyzing the reasons for the admission according to the order of hospitalization could not be reached. In our study, epistaxis was in the first place among the top five reasons for admission to the ED. In the first admission to the ED, mouth/gingival and melena/rectal bleeding were regarded as the second and third reasons, respectively.

In the second admission, hematuria was the most prominent type of hematuria, and in the third, mouth/gingival bleeding and ear bleeding were ranked.

In the third admission to the ED, melena/rectal bleeding and conjunctival bleeding came in the second and third place, respectively. Accordingly, the findings obtained from the present study were believed to contribute to the long-term follow-up of patients.

In our study, the other clinics in which the patients were hospitalized included cardiovascular 
surgery, cardiology, and neurology clinics. After evaluating the causes of hospitalization in the cardiovascular surgery clinic, wound infection was detected in $8(10.95 \%)$ patients. Wound infections are an important cause of morbidity and mortality after MHVRS. In a study on the incidence and risk factors of wound infection after cardiac surgery $(n=7170)$, wound infections were detected in 292 (4.1\%) cases (17). In another study, out of 114 patients with wound infection, 35 (30.7\%) cases were MHVRS patients. The sepsis rate in the study was determined at $69.5 \%(n=164)$. It had been reported that patients with positive culture results were within the age range of $60-76$ years (18). In our study, it was thought that $10.95 \%$ of the wound infection was due to the mean age of the patients (58.98 \pm 12.89 years) and the presence of comorbid diseases in $84.9 \%$ of the cases.

The most common places for admissions after cardiovascular surgery clinic included cardiology and neurology clinics. The patients were hospitalized due to cerebrovascular disease in the neurology clinic most frequently (Table 3 ). In a study conducted on patients with mechanical MVR, the rates of stroke incidence, trans ischemic attack, and valve thrombosis were obtained at 2.9\% $(n=4), 2.9 \%(n=4)$, and $1.4 \%(n=2)$, respectively (19).

The results of a population-based cohort study $(n=546)$ indicated that 16,30 , and 5 patients had cerebral, gastrointestinal, and fatal bleeding, respectively. After evaluating the thromboembolism cases, valve thrombosis, stroke, and peripheral thromboembolism were observed in 1, 32, and 3 patients, respectively (7). It was revealed that the consumption of the medications at the specified doses significantly reduced thromboembolic side effects, such as stroke, in patients using warfarin (20). The results also indicated that the developed thromboembolic complications after MHVRS might have resulted from the irregular consumption and lack of information about warfarin.

In the current study, one patient was admitted to the infection service due to postoperative sepsis, and one female patient developed an abortion after vaginal bleeding. Sepsis was one of the complications observed after cardiac surgery (3). In a study, sepsis was reported in $1.9 \%(n=2)$ of the patients after valve surgery $(n=23)(2)$. The females using warfarin should inform their healthcare team before planning for pregnancy. Otherwise, they may face complications during pregnancy (21). In a systematic review and meta-analysis on females with a prosthetic heart valve, eight perinatal deaths out of 124 births were found in women with mitral valve prolapse (22).

The patients' complications showed a significant difference with gender, presence of comorbidity, and monthly visits (Table 4). However, no relationship was found between the INR levels of the patients and the development of complications by months. On the other hand, in a study conducted by Bal et al. on the patients with mechanical MVR, there was a significant relationship between the log mean INR and all bleeding events; however, they found a negative correlation between thromboembolic events and log means (19). Another study reported no relationship between hospital admission and INR levels (14). In the present study, no difference could be explained by the low awareness of the patients. It was estimated that many patients developed complications (82.2\%) due to the low level of awareness and lack of referral for check-ups regularly (56.2\%).

The results of evaluating the INR values in this study indicated that the majority of values were not in the TTR (Table 4). In a study performed on patients with atrial fibrillation using warfarin $(n=300), 57 \%$ of the cases had no therapeutic INR level (23). According to the results of a study investigating the INR of the patients who were admitted to the ED and used warfarin, low $(2>)$, therapeutic (2-3), and high levels $(3<)$ were observed in $29(23.77 \%), 51$ (41.80\%), and 42 (34.42\%) patients, respectively (14). The results obtained from this study are consistent with the findings in the literature.

The therapeutic INR values were also investigated in this study by month. According to the results, the number of people above the TTR was higher in July, compared to the other months. Moreover, the number of people below the TTR was determined to be higher in January (Table 4). This result can be attributed to the warfarin-food interaction. The INR value decreases when the patients who take warfarin consume foods containing high vitamin $\mathrm{K}$ (21).

In this study, the INR values varied according to the seasons and months, as well as the fact that in the province where the study was conducted, weed and vegetable dishes were predominant in nutrition (24). Moreover, the number of people whose INR value was below the TTR was mostly in winter (January) due to the consumption of foods rich in vitamin $\mathrm{K}$, such as rocket, scallion, spinach, and cabbage in this season (25).

This study investigated the factors affecting the number of hospitalizations after MHVRS and reported a high number of hospitalizations of the patients who referred monthly for check-ups $(3.84 \pm 2.50)$, which was statistically significant $(\mathrm{t}=3.18, \mathrm{P}=0.002)$ (Table 5). It was recommended that these patients had at least one INR measured in four patients (26). In our study, more complications were observed in patients who were referred to the hospital, which could be explained by the diagnosis of complications during the check-ups when they went to the hospital. Furthermore, the development of complications was higher in patients who had previous valve surgery in this study $(Z=201.00$, $\mathrm{P}=0.03)$. 
Similar to our findings, in a study conducted by Akins et al., it was determined that the history of previous cardiac surgery in patients who underwent AVR affected the mortality and morbidity of the patients (27). Since redo valve surgeries involved more risks in terms of mortality and morbidity, compared to those who have surgery for the first time due to advanced age and comorbidities, more complications were expected in patients (28). Age and the time of the first hospitalization were not found to be effective in the number of hospitalizations. In addition, the number of hospitalizations increased as the postoperative period passed, and the duration of the surgery problem increased by an increase in the number of hospitalizations of the patients.

\subsection{Limitations}

When the patients refer to another hospital, their medical history is not available in the "Hospital Information System". Therefore, the number of hospital admissions might be higher, which is regarded as one of the limitations of the present study.

\section{Conclusion}

In this long postoperative period, it was observed that the patients were frequently admitted to the ED and struggled with various complications. It was also found that the patients had frequent bleeding and referred to the emergency service repeatedly. In addition to bleeding and thromboembolism, valve thrombosis, wound infection, and cerebrovascular diseases developed secondary to these patients. It was also observed that the follow-up of the patients was vital after discharge. Although warfarin was used for a long time, a high number of patients did not reach the therapeutic INR levels. There is a need for interventional studies to reduce postoperative complications and provide the therapeutic INR level of patients. In the postoperative period, consultancy programs can be created to enable patients to manage complications and reduce their admission to the ED. Furthermore, these consultancy programs and postoperative patient follow-up can be performed via telehealth or mobile applications. Further studies are also recommended to investigate the reasons for the lack of achieving the therapeutic INR level in patients. In addition, online training programs that improve patients' self-assessment of INR levels at home can be configured in this regard. When patients refer to another hospital, a "Hospital Information System" can be created to showing the medical history of that patient.

\section{Footnotes}

Conflict of Interests: The authors have no conflict of interest to declare.

\section{References}

1. Nishimura RA, Otto CM, Bonow RO, Carabello, BA, Erwin JP, Fleisher LA, et al. 2017 AHA/ACC Focused Update of the 2014 AHA/ACC guideline for the management of patients with valvular heart disease: a report of the American college of cardiology/American heart association task force on clinical practice guidelines. J Am Coll Cardiol. 2017;70(2):252-89. doi: 10.1016/j.jacc.2017.03.011. [PubMed: 28315732].

2. Howitt SH, Herring M, Malagon I, McCollum CN, Grant SW. Incidence and outcomes of sepsis after cardiac surgery as defined by the Sepsis-3 guidelines. Br J Anaesth. 2018; 120(3):509-16. doi: 10.1016/j.bja.2017.10.018. [PubMed: 29452807].

3. Karamnov S, Brovman EY, Greco KJ, Urman RD. Risk factors and outcomes associated with sepsis after coronary artery bypass and open heart valve surgeries. Semin Cardiothorac Vasc Anesth. 2018;22(4):359-68. doi: 10.1177/1089253218785362. [PubMed: 29992859].

4. Bouhout I, Stevens LM, Mazine A, Poirier N, Cartier R, Demers P, et al. Long-term outcomes after elective isolated mechanical aortic valve replacement in young adults. $J$ Thorac Cardiovasc Surg. 2014;148(4):1341-6.e1. doi: 10.1016/j.jtcvs.2013.10.064. [PubMed: 24332113].

5. Havers-Borgersen E, Butt JH, Vinding NE, Torp-Pedersen C, Gislason G, Køber L, et al. Time in therapeutic range and risk of thromboembolism and bleeding in patients with a mechanical heart valve prosthesis. I Thorac Cardiovasc Surg. 2019; 159(1):74-83. doi: 10.1016/j.jtcvs.2019.02.061. [PubMed: 30961980].

6. Lee H, Sung K, Kim WS, Jeong DS, Ahn JH, Carriere KC, et al. Late clinical outcomes after mechanical aortic valve replacement for aortic stenosis: old versus new prostheses. J Thorac Dis. 2018;10(6):3361-71. doi: 10.21037/jtd.2018.06.03. [PubMed: 30069331].

7. Labaf A, Grzymala-Lubanski B, Stagmo M, Lövdahl S, Wieloch M, Själander A, et al. Thromboembolism, major bleeding and mortality in patients with mechanical heart valves-a population-based cohort study. Thromb Res. 2014;134(2):3549. doi: 10.1016/j.thromres.2014.06.007. [PubMed: 24985036].

8. Labaf A, Själander A, Stagmo M, Svensson PJ. INR variability and outcomes in patients with mechanical heart valve prosthesis. Thromb Res. 2015;136(6):1211-5. doi: 10.1016/ j.thromres.2015.10.044. [PubMed: 26558830].

9. Demir Korkmaz FA, Okgün Alcan AL, Karacabay K. Do patients with mechanical heart valves have the appropriate knowledge regarding warfarin therapy and can they adhere to the correct dosage? Turk Gogus Kalp Damar. 2015;23(1):58-65. doi: 10.5606/tgkdc.dergisi.2015.10390.

10. Demirel E, Uzun Ş. Determination of factors affecting effective INR (International Normalization Ratio) value in individuals using warfarin. Turk J Cardiovasc Nurs. 2018;9(19):58-68. doi: 10.5543/khd.2018.86580.

11. Kılıç S, Çelik A, Çakmak HA, Afșin A, Tekkeșin Aİ, Açıksarı G, et al. The time in therapeutic range and bleeding complications of warfarin in different geographic regions of Turkey: a subgroup analysis of WARFARIN-TR Study. Balkan Med J. 2017; 34(4):349-55. doi: 10.4274/balkanmedj.2016.1617. [PubMed: 28443575].

12. Celik A, İzci S, Kobat MA, Ateş AH, Çakmak A, Çakılll, Y, et al. The awareness, efficacy, safety, and time in therapeutic range of warfarin in the Turkish population: WARFARIN-TR. Anatol $J$ Cardiol. 2016;16(8):595-600. doi: 10.5152/AnatolJCardiol. 2015.6474. [PubMed: 27004711].

13. Kilic S, Saracoglu E, Qekici Y, Kilic DD, Yildirim A, Kuzu Z. Effects of regular follow-up on quality of life and warfarin efficiency in rural patients. Eur J Ther. 2019;25(3):183-9. doi: 10.5152/EurJTher.2018.602.

14. Temrel TA, Şahin S, Şan ŞA. What is the success rate of patients using warfarin in maintaining their target international 
normalized ratio levels? Ankara Med J. 2019;19(2):366-74. doi: 10.17098/amj.577304.

15. Koçak S, Ertekin B, Öztürk EE, Dündar ZD, Acar T, Girişgin AS. Bleeding due to warfarin treatment: five years of experience. Turk Klinikleri Cardiovasc Sci. 2019;31(3):125-34. doi: 10.5336/cardiosci.2019-65895.

16. Beyan E, Beyan C, Vaizoğlu SA. Predisposing preventable factors in patients with bleeding due to warfarin usage: evaluation of 114 patients. Clin Appl Thromb Hemost. 2010;16(6):684-7. doi: 10.1177/1076029609338049. [PubMed: $19520686]$.

17. Bal U, Aydinalp A, Yilmaz K, Ozcalik E, Hasirci S, Atar I. The effects of a low international normalized ratio on thromboembolic and bleeding complications in patients with mechanical mitral valve replacement. J Cardiothorac Surg. 2014;9(1):79. doi: 10.1186/1749-8090-9-79. [PubMed: 24885719].

18. Valeur N, Mérie C, Hansen ML, Torp-Pedersen C, Gislason GH, Kober L. Risk of death and stroke associated with anticoagulation therapy after mitral valve repair. Heart. 2016;102(9):687-93. doi: 10.1136/heartjnl-2015-308272. [PubMed: 26729693].

19. Lemaignen A, Birgand G, Ghodhbane W, Alkhoder S, Lolom I, Belorgey $S$ et al. Sternal wound infection after cardiac surgery: incidence and risk factors according to clinical presentation. Clin Microbiol Infect. 2015;21(7):674-e11-8. doi: 10.1016/ j.cmi.2015.03.025. [PubMed: 25882356].

20. Kotnis-Gąska A, Mazur P, Olechowska-Jarząb A, Stanisz A, Bulanda M, Undas A. Sternal wound infections following cardiac surgery and their management: a single-centre study from the years 2016-2017. Kardiochir Torakochirurgia Pol. 2018;15(2):79-85. doi: 10.5114/kitp.2018.76472. [PubMed: 30069187].

21. Saksena D, Muralidharan S, Mishra YK, Kanhere V, Mohanty BB,
Srivastava CP, et al. Anticoagulation management in patients with valve replacement. J Assoc Physicians India. 2018; 66(1):59-74. [PubMed: 30341847].

22. Lawley CM, Lain SJ, Algert CS, Ford JB, Figtree GA, Roberts CL. Prosthetic heart valves in pregnancy, outcomes for women and their babies: a systematic review and meta-analysis. BJOG. 2015;122(11):1446-55. doi: 10.1111/1471-0528.13491. [PubMed: 26119028].

23. Demir N, Yıldırım Yücelen S, Güven Çetin E, Erol Kalkan K, Öztürkmen YA, Demir E, et al. Determination of INR awareness and achievement rates in patients using warfarin. Sisli Etfal Hostan Tip Bul. 2019;54(3):357-63. doi: 10.14744/SEMB.2019. 76993. [PubMed: 33312036].

24. Sengul S. Determining the gastronomic tourism destinations of turkey: a case of domestic tourists. Balıkesir Univ J Soc Sci Instit. 2017;20(37):375-96.

25. Sarıkamis G. Health source of our table: winter vegetables. Turk Seed Growers Assoc. 2016;5(20):51-7.

26. Ansell J, Hirsh J, Hylek E, Jacobson A, Crowther M, Palareti G. Pharmacology and management of the vitamin $\mathrm{K}$ antagonists: American College of Chest Physicians Evidence-Based Clinical Practice Guidelines (8th Edition). Chest. 2008;133 (6 Suppl):160S-98S. doi: 10.1378/chest.08-0670. [PubMed: 18574265].

27. Akins CW, Hilgenberg AD, Vlahakes GJ, Madsen JC, MacGillivray TE. Aortic valve replacement in patients with previous cardiac surgery. J Card Surg. 2004;19(4):308-12. doi: 10.1111/j.08860440.2004.4055_11.x. [PubMed: 15245459].

28. Crawford TC, Magruder JT, Grimm JC, Suarez-Pierre A, Sciortino CM, Mandal K, et al. Complications after cardiac operations: all are not created equal. Ann Thorac Surg. 2017;103(1):32-40. doi: 10.1016/j.athoracsur.2016.10.022. [PubMed: 27884410]. 